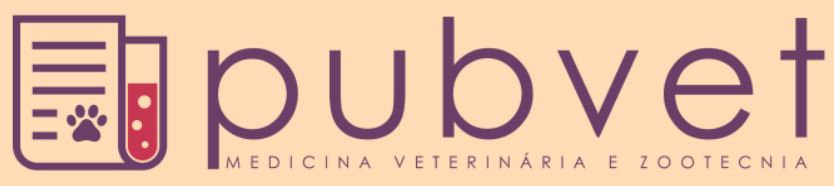

HTTP://DX.DOI.ORG/10.22256/PUBVET.V11N1.50-54

\title{
Tétano em um equino: Relato de caso
}

\section{Matheus Hernandes Leira ${ }^{1 *}$, Mariella Pereira de Oliveira ${ }^{2}$, Lucas Silva Reghim ${ }^{3}$, Ana Paula Peters $^{2}$, Lucas Pereira Spósito de Almeida ${ }^{4}$, Mirian Silvia Braz ${ }^{5}$, Vanessa Sobue Franzo $^{6}$}

\author{
${ }^{I}$ Professor Titular e Pesquisador do Curso de Medicina Veterinária - Centro Universitário do Sul de Minas - UNIS, Brasil \\ ${ }^{2}$ Médica Veterinária autônoma, Brasil \\ ${ }^{3}$ Aluno do Curso de Medicina Veterinária - Centro Universitário do Sul de Minas - UNIS Brasil \\ ${ }^{4}$ Aluno do Curso de Medicina Veterinária - Universidade Federal de Lavras - UFLA, Brasil \\ ${ }^{5}$ Mestre em Ciências Veterinárias, Universidade Federal de Lavras - UFLA Brasil \\ ${ }^{6}$ Professora Adjunta e Pesquisadora, Universidade Federal de Mato Grosso, Cuiabá - UFMT, Brasil \\ *Autor para correspondência matheus.hernandes@unis.edu.br
}

RESUMO. O tétano é uma doença causada pelas toxinas tetanolisina, tetanoespasmina e toxina não espasmogênica, produzidas pela bactéria Clostridium tetani em anaerobiose. Foi atendido um equino da raça manga larga marchador, fêmea de 8 anos de idade, pelagem Tordilha e peso de $400 \mathrm{~kg}$, no exame clínico o animal apresentava andar em forma de cavalete, calda semi erguida e quando manipulada o cabreiro ela apresentava protrusão da terceira pálpebra, não havia machucados, foi examinado os cascos, bem como todo o corpo do animal e não foi encontrado nada, com base no exame físico do animal, bem como os sinais clínicos apresentados o diagnóstico de tétano foi estabelecido. O tratamento foi imediato instituído com soro antitetânico por via intravenosa, terapia com antibióticos e a terapia com relaxantes musculares. O animal se recuperou após 20 dias de tratamento.

Palavras chave: Equinos, clostridium tetani, toxinas

\section{Tetanus in an equine: Case report}

ABSTRACT. The tetanus is a disease caused by toxins tetanolysin, tetanopasmina not spasmogenic toxin produced by Clostridium tetani bacteria anaerobically. Was served a horse of marchador long-sleeved race, female 8 years old, dark gray coat and weight of 400 $\mathrm{kg}$, the clinical examination the animal had floor-shaped rack, syrup semi erected and when manipulated the goatherd she had third protrusion eyelid was not injured was examined hulls as well as the whole body of the animal and nothing has been found based on the animal physical examination, and clinical signs presented tetanus diagnosis was established. The treatment was immediately established tetanus serum intravenous antibiotic therapy and therapy with muscle relaxants. The animals recovered after 20 days of treatment.

Keywords: Equines, Clostridium tetani, Toxins

\section{Tétano en equino: Reporte de un caso}

RESUMEN. El tétano es una enfermedad causada por las toxinas tetanolisina, tetanospasmina y toxina no espasmogénica, producidas por la bacteria Clostridium tetani en anaerobiosis. Fue atendido un equino de la raza manga larga marchador, Hembra de 8 años de edad, pelaje Tordilla y peso de $400 \mathrm{~kg}$, durante el examen clínico el animal presentaba andar en forma de caballete, cola semi levantada y cuando manipulada el cabrero esta presentaba protrusión de la tercera pálpebra, no había lesión, fueron 
examinados los cascos, así como todo o cuerpo del animal y no fue encontrado nada, En base al examen físico del animal, conforme los signos clínicos presentados el diagnóstico de tétano fue establecido. El tratamiento fue inmediatamente instituido con suero antitetánico por vía intravenosa, terapia con antibióticos y terapia con relajantes musculares. El animal se recuperó después de 20 días de tratamiento.

Palabras clave: Equinos, Clostridium tetani, toxinas

\section{Introdução}

As clostridioses incluem várias espécies de Clostridium, que acometem diversas espécies animais, tanto de produção quanto selvagem. Nos animais de interesse pecuário, os clostridios são extremamente importantes, pois atuam como agente primário da doença (Blencowe et. al., $\underline{2010}$ ).

O tétano é considerado uma tóxica infecciosa, já que $o$ Clostridium tetani produz as toxinas que desencadeiam a doença. É uma enfermidade de grande importância na clínica veterinária, devido à elevada taxa de mortalidade e longo período de convalescença (Thomassian, 2006).

O tétano ocorre em todo mundo, sendo mais frequente em áreas muito utilizadas para cultivo intensivo. Ocorre em todos os animais pecuários, sobre tudo na forma de casos individuais, esporádicos embora surtos sejam observados, ocasionalmente, em cordeiros, bovinos e suínos, bem como em equinos após a realização de práticas de manejo traumatizantes (Smith, 2006).

O Clostridium tetani, é uma bactéria gram positiva, que pode ser encontrada sob forma vegetativa ou esporulada em função das condições de tensão de oxigênio no ambiente, pode ser isolado do conteúdo gastrointestinal dos herbívoros, sendo a contaminação fecal responsável pela propagação das bactérias no solo. As formas esporuladas do Clostridium tetani são encontradas em maior frequência em regiões tropicais e terrenos abandonados, onde são realizadas atividades agropecuárias e podem permanecer viáveis por anos (Trindade and Trindade, 2006). Entretanto, pode ser considerado um contaminante primário de solo, pois são encontrados onde não há presença de rebanhos (Thomassian, 2006).

As feridas, infecções do ônfalo, abscessos causados pela aplicação de injeção, infecções uterinas, feridas puntiformes nos cascos ou tecidos moles são locais propícios para a proliferação do Clostridium tetani devido à formação de anaerobiose. Também pode ocorrer infecção bacteriana secundária, necrose tecidual, acúmulo de pus e presença de corpos estranhos ( $\underline{\text { Smith}}$, 2006).

Nessas feridas quando há condições ideais de baixa tensão de oxigênio há a multiplicação do Clostridium tetani e produção de três toxinas: tetanospasmina, tetanolisina e uma toxina não espasmogênica. As toxinas são destruídas pelo suco gástrico, são termo resistentes, e dificilmente absorvidas pela mucosa. A tetanolisina é uma hemolisina promotora de necrose tecidual local, favorecendo a multiplicação e disseminação do Clostridium tetani (Corrêa \& Corrêa, 1992).

A tetanospasmina é a toxina neurogênica, que depois de produzida, difunde-se pela circulação sanguínea até os nervos periféricos (Lima et al., 2013). A tetanospasmina parece agir inibindo a liberação de glicina, neurotransmissor que promove a descontração muscular, desse modo, a musculatura permanece contraída, observando-se assim a espasticidade (Corrêa \& Corrêa, 1992).

Existe também a produção de uma toxina não espasmogênica que causa alguns fenômenos autônomos que são resultado da hiperestimulação do sistema nervoso simpático (Smith, 2006). Os surtos são relacionados com higiene precária de instalações e utensílios utilizados no manejo dos animais (Zappa and Francisco, 2013).

Para a manifestação clínica do tétano é necessário ferimento ou solução de continuidade que possibilite a introdução da bactéria (Quevedo et al., 2011). O diagnóstico de tétano geralmente é baseado nos sinais clínicos, que são característicos, e no histórico de trauma, tosquia, castração ou qualquer outro manejo que possa gerar uma porta de entrada para o agente. No entanto, pode ser realizada uma série de provas bioquímicas e biológicas que confirmem a suspeita clínica (Zappa and Francisco, 2013).

O diagnóstico do tétano é realizado com base nos sinais clínicos apresentados pelos animais. Eliminar a fonte de bactérias e toxinas do organismo animal, controlar os espasmos musculares e fornecer tratamento suporte como hidratação e nutrição são fundamentais para um tratamento eficaz. Embora o prognóstico seja 
considerado reservado, há variação conforme o tempo de evolução e intensidade dos sinais clínicos. Considerando a taxa de mortalidade em equinos de até $80 \%$, é fundamental manter um controle e profilaxia adequados, sendo o mais efetivo a imunização, feita através de vacinas, devendo ser mantido um cronograma de vacinação anual (Silva et al., 2010).

O prognóstico depende da gravidade dos sinais clínicos e da velocidade da evolução da doença. O rápido aparecimento de sinais clínicos geralmente denota prognóstico mais cauteloso, assim como a posição de decúbito dorsal prolongado. De acordo com os dados existentes, as taxas de mortalidade variam de 50 a 75\% (Rocha Júnior, 2011)

O objetivo do presente trabalho é relatar um caso clinico de tétano em equino atendido na Fazenda Vargem Alegre no Município de Cabo Verde, Sul do estado de Minas Gerais.

\section{Relato de caso}

Um equino da raça manga larga marchador, fêmea de oito anos de idade, pelagem Tordilha e peso de $400 \mathrm{~kg}$, o Médico Veterinário foi chamado para fazer atendimento sendo que o proprietário suspeitava de aborto, pois havia banhado com carrapaticida, segundo ele a gestação era de três meses. No exame clínico o animal apresentava andar em forma de cavalete, calda semi erguida e quando manipulada o cabreiro ela apresentava protrusão da terceira pálpebra, não havia machucados, foi examinado os cascos, bem como todo o corpo do animal e não foi encontrado nada.

Com base no exame físico do animal, bem como os sinais clínicos apresentados o diagnóstico de tétano foi estabelecido e encaminhamos o animal para uma baía escura, introduzimos algodão nos ouvidos, e começou o tratamento imediato instituído foi 50.000 UI de soro antitetânico por via intravenosa. A terapia com antibióticos foi realizada utilizando com pencivet plus $40.000 \mathrm{UI} / \mathrm{kg}$, uma vez a cada 48 horas e a terapia com relaxantes musculares foi feita de acordo com a apresentação do animal.

O fármaco utilizado foi a acepromazina na dose de $0,01 \mathrm{mg} / \mathrm{kg}$, três vezes ao dia por 8 dias. Foi oferecido medicação de suporte, soroterapia e vitaminas do complexo B, catosal B12, durante 10 dias, o que resultou na melhora do animal.

Os exames físicos foram realizados uma vez ao dia, porém o animal foi submetido as observações frequentes ao longo dos dias. Nos exames físicos não havia variações: a frequência cardíaca sempre se manteve em torno de 44 batimentos por minuto (bpm), a frequência respiratória em torno de 40 movimentos por minuto (mpm), a temperatura próxima a $38,0^{\circ} \mathrm{C}$, e a motilidade intestinal normal em todos os quadrantes abdominais, o animal se alimentava e defecava normalmente, apesar do pouco trismo mandibular. A partir do $6^{\circ}$ dia houve uma diminuição da espasticidade, melhora da rigidez, da mastigação, da hiperestesia sendo a partir de então administrado o acepromazina duas vezes ao dia. A partir do $10^{\circ}$ dia de tratamento não foi realizada nenhuma medicação, houve melhora diária da espasticidade, da hiperestesia. $\mathrm{O}$ animal se alimentou adequadamente com feno e capim verde, e conseguia ingerir água. No $10^{\circ}$ dia, devido à melhora significativa da espasticidade $\mathrm{e}$ da rigidez, houve a retirada dos protetores auriculares e o animal ficou em observação por mais 10 dias e obteve alta.

\section{Discussão}

Com base nos sinais clínicos característicos da doença, dados da anamnese e exame físico do paciente o diagnóstico de tétano foi estabelecido. A hiperestesia, espasticidade, posição de cavalete, cauda em bandeira, pescoço estendido, prolapso de $3^{\circ}$ pálpebra, enrijecimento muscular da cabeça e pescoço, trismo mandibular e intensa sudorese são sinais característicos de tétano, observados devido à ação das toxinas: tetanopasmina, tetanolisina e uma toxina não espasmogênica (Smith, 2006; Lima et al., 2013). A produção dessas toxinas ocorre devido à criação de um ambiente de anaerobiose em feridas, nos abscessos causados pela aplicação de injeção, nas feridas puntiformes nos cascos ou tecidos moles (Lima et al., 2013).

$\mathrm{O}$ equino do presente relato foi inspecionado nos cascos e todo o corpo, entretanto nenhuma ferida foi encontrada. Acredita-se que a bactéria tenha sido inoculada por injeções intramusculares realizadas sem qualquer cuidado de antissepsia e uso de seringas e agulhas não estéreis. $O$ fato de não se encontrar a fonte de produção de toxinas tem grande valor no prognóstico de cada animal, pois é impossível eliminar as bactérias que produzem essas toxinas. Em um estudo clínico em equinos com tétano, realizado por Reichmann et al. (2008), os equinos foram inspecionados e quando a ferida não foi encontrada a mortalidade dos animais alcançou $100 \%$, diferentemente do animal do presente relato. 
A eficiência do tratamento consiste na eliminação da bactéria causadora, neutralizar a toxina residual, controlar os espasmos musculares, curativos de feridas se presente, manter a alimentação, hidratação e também fornecer tratamento suporte como baias com cama alta, ausência de barulho, e escura (Reichmann et al., 2008). O tratamento realizado seguiu o que está preconizado na literatura mundial (Smith, 2006; Reichmann et al., 2008; Radostits et al., 2010; Lima et al., 2013). A neutralização da toxina circulante foi realizada com 50.000 UI de soro antitetânico por via intravenosa. A escolha dessa dosagem é empírica pois não há estudos controlados que sugerem a dosagem adequada para cada paciente (Reichmann et al., 2008). Foram aplicados tampões auriculares de algodão e o animal ficou em baia escura sem ruídos sonoros.

No presente relato a acepromazina foi utilizada como sedativo e relaxante muscular na dosagem de $0,01 \mathrm{mg} / \mathrm{kg}$ (Mackay and Mayhew, 1972). A aplicação deste fármaco a cada oito horas foi eficaz para controle dos espasmos e sedação leve do paciente, sem necessidade de aumento de dose e frequência.

Alguns estudos relatam a eficiência da aplicação de soro antitetânico por via intratecal no espaço atlanto-occipital, ou no lombo-sacro para neutralização da toxina livre no sistema nervoso central (Silva et al., 2010).

No presente relato, a aplicação intratecal da antitoxina tetânica não foi realizada e o animal se recuperou prontamente, a administração intratecal requer anestesia geral e pode gerar complicações como infecções iatrogênicas, piora da espasticidade devido à manipulação, morte durante à anestesia geral o que torna a viabilidade desta técnica altamente questionável, visto que de acordo com alguns autores a toxina não se encontra livre no sistema nervoso central, portanto só é susceptível a neutralização antes de se ligar as células nervosas (Mackay and Mayhew, 1972).

O prognóstico da doença está diretamente ligado à velocidade de evolução da mesma, sendo considerado mal quando é de evolução rápida e reservado quando é de evolução lenta e mais branda (Radostits et al., 2010).

Estudo realizado por Reichmann et al. (2008) percebeu-se que quando o tempo de hospitalização do paciente é superior há 7 dias a taxa de sobrevivência é de $100 \%$ dos casos, o presente relato corrobora esta afirmação, visto que o equino permaneceu em observação por 20 dias.

$\mathrm{O}$ animal respondeu satisfatoriamente ao tratamento e recebeu alta vinte dias após o início do mesmo. O prognóstico da doença está diretamente ligado à velocidade de evolução da mesma, sendo considerado desfavorável quando é de evolução rápida e favorável quando de evolução lenta e mais branda (Radostits et al., 2010). No paciente do presente relato, apesar de evolução rápida, a resposta ao tratamento foi satisfatória. Embora o diagnóstico seja simples, é importante a diferenciação do tétano de outras enfermidades, como o envenenamento por estricnina (que acomete vários animais ao mesmo tempo), tetania hipocalcêmica (restringe-se a éguas prenhes e responde ao tratamento com cálcio), laminite aguda (não apresenta protrusão de terceira pálpebra), meningite cérebro-espinhal (provoca mais depressão e imobilidade) e miosite (normalmente após aplicação de injeções no pescoço).

\section{Conclusão}

$\mathrm{O}$ tétano em equinos, devido à alta susceptibilidade dessa espécie, e ao seu prognóstico reservado se constitui um problema que merece uma atenção especial. A vacinação é o método ideal para se evitar o acometimento dos animais por essa doença, porém medidas profiláticas complementares, especialmente no que diz respeito ao manejo dos animais, são medidas fundamentais para diminuir significativamente $\mathrm{o}$ risco que o tétano nos equinos.

\section{Referências Bibliográficas}

Blencowe H, Lawn J, Vandelaer J, Roper M \& Cousens S. 2010. Tetanus toxoid immunization to reduce mortality from neonatal tetanus. International Journal of Epidemiology, 39, 102-109.

Corrêa, W. M. \& Corrêa, C. N. M. 1992. Enfermidades infecciosas dos Animais Domésticos. 2.ed. São Paulo: Medsi, 843p.

Lima, J.T.B., Patrício, L.A.M.M., Amorim , F.A.F., Santos, S.G., Baptista Filho, L.C.F.B., 2013. Tétano em equino - relato de caso, In: Recife, U.F.d. (Ed.), Jornada de ensino, pesquisa e extensão, Recife.

Mackay, R.J., Mayhew, I.G., 1972. Tetanus, In: Catcott, E.R., Smithcors, J.F. (Eds.), Equine 
medicine and surgery., American Veterinary Publications, pp. 785-788.

Quevedo, P.S., Ladeira, S.R.L., Soares, M.P., Marcolongo-Pereira, C., Sallis, E.S.V., Grecco, F.B., Estima-Silva, P., Schild, A.L., 2011. Tétano em bovinos no sul do Rio Grande do Sul: estudo de 24 surtos. Pesqui. Vet. Bras. 31, 1066-1070.

Radostits, O.M., Gay, C.C., Blood, D.C., Hinchcliff, K.W., McKenzie, R.A., 2010. Clínica Veterinária: um tratado de doenças dos bovinos, ovinos, suínos, caprinos e eqüinos. Guanabara Koogan, Rio de Janeiro.

Reichmann, P., Lisboa, J.A.N., Araujo, R.G., 2008. Tetanus in equids: A review of 76 cases. Journal of Equine Veterinary Science 28, 518523.

Rocha Junior, P. S. 2011. Tétano em bovinos no sul do Rio Grande do Sul: estudo de 24 surtos. Pesquisa Veterinária Brasileira. 31, 10, 10661070.

Silva, A.A., Stelmann, U.J.P., Papa, J.P., Fonseca, E.F., Ignácio, F.S., Ferreira, J.C., Ribeiro Filho, J.D., 2010. Uso de antitoxina tetânica por via intratecal e endovenosa no tratamento de tétano acidental em equino: Relato de caso. Revista Científica Eletrônica de Medicina Veterinária, 14, 1-11.

Smith, M.O., 2006. Doenças do sistema nervoso, In: Smith, B.P. (Ed.), Tratado de medicina interna de grandes animais, Manole, São Paulo, pp. 995-996.

Thomassian, A., 2006. Enfermidades dos cavalos. Livraria Varela, São Paulo.

Trindade, R.R.R., Trindade, W.M., 2006. Tétano Felino-relato de caso. Revista Nosso Clínico 50, 30-36.

Zappa, V., Francisco, L., 2013. Tétano em equinos - Revisão de literatura. Revista Científica Eletrônica de Medicina Veterinária 21, 1-7.

\section{Article History:}

Received 17 October 2016

Accepted 3 November 2016

Available on line 22 December 2016

License information: This is an open-access article distributed under the terms of the Creative Commons Attribution License 4.0, which permits unrestricted use, distribution, and reproduction in any medium, provided the original work is properly cited. 